\title{
5
}

\section{Kant and Arendt on the Challenges of Good Sex and the Temptations of}

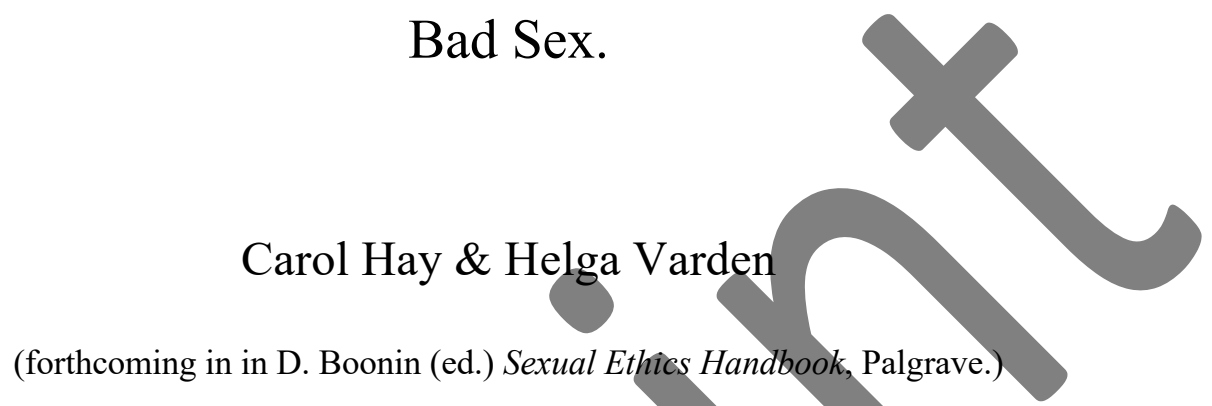

Introduction*

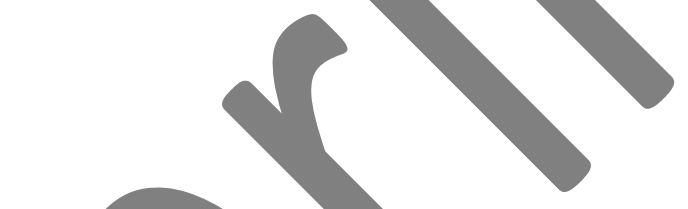

A good philosophical account of human sexual love requires an account of our animalistic desires. Although certain aspects of sexual desires don't require such a reference-for example, some aspects can be analyzed by reference to our imaginative minds and social senses of self-a full account of human sexual desires is impossible without an account of our animality. After all, sexual desire is something we feel in a distinctly embodied, animalistic way: when I-that is, subjectively, from an internal, self-conscious first-personal point of view-feel sexual desire very strongly, I feel my body very strongly. When I feel my body in this way I strongly want or long for the attention, and typically touch, of another, along with some kind of intimacy and/or physical union with them.

Conversely, when I am experiencing sexual frustration, I may, for example, feel my body as a little in the way, as annoyingly and persistently demanding attention, or as betraying me by making me focus on something I don't really want to focus on, namely sexual satisfaction in 
general or with regard to some person(s) in particular. Alternatively, sexual frustration can manifest as the body being experienced as having an unfulfilled hunger or appetite, such as when you want to orgasm but can't achieve it—which is a little like having an itch that you can't scratch or being thirsty with no water available. Sexual frustration can also be the opposite: you might be able to bring yourself to orgasm, but you don't enjoy the process leading to it, so you sprint for a somewhat unsatisfying end. Another kind of frustrated sexual desires involves experiencing your body as betraying you because it makes you feel sexual desires that you do not know how to own or manage, or that make you feel ashamed, embarrassed, or vulnerable. For example, if you have been taught that the only "normal" sexual desires are heterosexual and procreative in nature, finding yourself in situations where you feel a desire that doesn't fit this conception of good sexual love can make you feel betrayed by your body.

What is it about our nature that makes us feel in these ways or have these desires? What is their value (if any)? How we can realize them well? Part of the challenge of articulating a philosophical account that can answer these questions is that having sexual desires is not, as such, distinctive of human being non-human animals have these desires too, though somewhat differently. Good philosophical accounts of sexual love therefore need to capture both the similarities and the differences between human and other animals' sexual desires, including how only human animals are morally responsible for their sexual desires—-for developing, transforming, and integrating them into their lives in good ways. In philosophical accounts of human nature, the exploration of these themes therefore non-accidentally involves an analysis of human animality, including how it is complemented by our distinctively human biological, social, aesthetic, rational, and temperamental aspects. In addition, such accounts must address 
our human tendency to engage in self-destruction, or the destruction of others, by disrespecting or attacking our sexually loving aspects.

Sexual love was not Hannah Arendt's intellectual focus, and many of Immanuel Kant's writings on the topic appear unpromising and hostile or even antithetical to any interesting theory of sexual love. ${ }^{i}$ Despite this, in what follows we use philosophical resources they left us to explore these themes. In particular, we propose that Kant's account of human nature—good and bad-in conjunction with some of Arendt's thoughts on the problems with the Western philosophical tradition's engagement with animality, yield a good starting point for exploring the nature and value of good sexual love for many.

In Kant's philosophical framework, understanding sexual love requires an analysis of how we develop our "natural vital force" through our "animality" (our conscious strivings for self-preservation, sex, and affectionate community), which is distinct from and yet is also integrated, developed, and transformed by our "humanity" (our social sense of self and capacity to set ends of our own rationally), our "personality" (our moral feeling or moral vital force, or our ability to act as motivated by practical reasons), and our aesthetic-teleological abilities (our susceptivity to aesthetic pleasures and to engage the world through parts-and-wholes ${ }^{\mathrm{ii}}$ rationality). Moreover, our analysis of sexual wrongdoing will use Kant's account of our propensity to evil, which includes an analysis of how affect and passions block or corrupt our thinking powers such that we neither experience ourselves as harmonious nor as rationally coherent and properly responsive to calls from our conscience. (More on this shortly. ${ }^{\mathrm{iii}}$ ) In Arendt's (Heidegger-inspired) framework, correspondingly, sexual love becomes determined by how one views the elements of what she calls "labor" (reproductive activity, which is sustaining of biological life and grounding of a private life), "work" (human life as 
enabled by our capacity for creating a human world by crafting useful objects, such as roads and houses and tools); "action" (human political life as enabled by our individual ability to use speech and act spontaneously to create a political society with a history); and "thought" (human theoretical life, including academic life as enabled by our ability to think and reason through abstract concepts). ${ }^{\text {iv }}$ Moreover, on her account, human evil centrally involves our inability to orient ourselves by a commitment to truthfulness and rational coherence in response to facts. ${ }^{\mathrm{v}}$ She relatedly and (in)famously proposes that some of the worst of evils are "banal,",vi which she later explores through the concept of "thoughtlessness." "vii Like Kant, she thinks that human evil is characterized by incoherence and conflict internal to each person.

Arendt is one of the richest thinkers on the human tendency to evil, and one of her remarkable theoretical abilities is to identify blind spots and unintended consequences of assumptions or practices in the Western philosophical tradition. One such suggestion is that philosophy as a practice typically has ranked these various valuing activities (animalistically, biologically, socially, aesthetically, rationally) in a hierarchy, where philosophical contemplation reigns at the top. In contrast, activities involving labor (in her system) or our animality (in Kant's system) are typically found towards the bottom of the scheme. She proposes that this philosophical practice is interwoven with societal practices and structures, such as the activity of labor or our animality being the work of "natural slaves" or women, and as inherently private (in the home) rather than public in nature. In contrast, philosophy has typically identified the highest human ideal — the one closest to being as such or god — as philosophical search for eternal truths. The best human life, therefore, is thought to be philosophical contemplation of eternal principles constitutive of the universe (and not merely the earth), principles that our rational capacities are seen as giving us access to. One benefit of Arendt's analysis is that it enables us to see how 
racist, sexist, and heterosexist thoughts in classical philosophical texts often are internally related to a general disdain for animality. It can also help us see how members of these groups are often closely associated with their animality (so understood), and hence, like other animals, viewed as permissible to use or as needing to be controlled or managed. And it can help us see how these people are sometimes viewed as needing to be corrected or stopped, because they are allegedly even perverting animality. Moreover, since our animality in general has been viewed as a constitutive or primary component in private activities - the sphere of women and slaves - it follows that we should not give it priority in our lives if we can, and those who value or even prioritize engaging in these activities reveal their lower or perverted nature (or soul), namely one that seeks to function only in accordance with our "merely" biological, reproductive, or animalistic desires. Needless to say, on such conceptions, envisioning diverse, flourishing sexually loving human lives consistent with human dignity becomes impossible.

In The Human Condition, Arendt suggests that in modern life this traditional problem of philosophy has become a wider problem of society. She suggests that the problems related to a wrongly devalued animality moved from being primarily a philosophical problem—and possibly a problem for philosophers' lives- to becoming a general societal problem because modern technology and labor movements enabled the material conditions of human life to become less preoccupied by domestic life-sustaining activities. This also led to a blurring of distinctions between different kinds of valuing activities, and a lack of appreciation of the differences between the private and the public spheres, which in turn fostered overblown social senses of self. As contemporary social media shows so clearly, we have a serious temptation not to protect our own private lives and to let our sense of ourselves be determined by how others see us. As 
we will see in the final section, this analysis is helpful for shedding light on some of the challenges facing anyone who wants to realize a flourishing sexually loving life.

In the next section, in contrast, we put forward a Kantian account of human nature, and an interpretation of central features of good sex, that can overcome this problem in the philosophical tradition—including in much Kantian philosophical thought—and in modern human practice. More specifically, we use the writings of Kant to develop an account of the resources and challenges internal to us - as emotionally complex, particular human beings - that make sexual love a joyous and deeply meaningful, yet also difficult life-long project to realize in good, sustainable ways. We argue that on this approach, good sexual love channels sexual desire that is grounded in our natural vital force in ways that are in line with our temperaments, are aesthetically and teleologically pleasing to us, and are pursued within moral boundaries set by our genuine commitment to truthfulness and to treating ourselves and others as having dignity. Hence, good sexual love non-accidentally involves being able to do things like form meaningful (even if not necessarily permanent nor even long-lasting) relationships of vulnerable and yet empowering intimacy with others, to appreciate and enjoy one's own embodiment in self- and other-regarding ways that are nourishing or conducive to flourishing, to become increasingly able to be genuinely curious, kind, open-minded, stabilizing, and playful around one's own and others' good sexual ways. This enables us, in section three, to focus on specific patterned challenges that face us given the modern historical societies — with their oppressive forces — we are inheriting.

\section{Human Animality}


In our view, good philosophical accounts of animality must accommodate the fact that many people experience certain distinctive and relatively constant fundamental drives in their sexually loving ways, both with respect to how they prefer their own body to be in these regards and to their preferences regarding others' sexually complementing bodies. That is to say, whether the focus is on sexual orientation or gender identity, a central component behind all of the letters LGBTQIA concerns how we experience ourselves as embodied, sexually loving beings. In the Kantian philosophical framework, some of this requirement can be captured by Kant's account of how sexual love necessarily involves our natural vital force as given direction by our animalistic sexual drive.

Second, on this Kantian account, our animalistic sexual drive is understood as fundamentally only reflexively, and not also reflectively, self-conscious. ${ }^{\text {vii }}$ This proposal opens up the possibility of a third option when it comes to sexual/gender identity and sexual orientation, between so-called (rationalistic or empirical) "essence" and (existential or constructivist) "choice" accounts. ${ }^{\mathrm{ix}}$ Rather than viewing our sexually loving ways as something that is given at birth and then realizes itself through us more or less successfully (as many empiricist and rationalist essence accounts ultimately do) or as something we ultimately simply choose in more or less free ways (as many existentialist and (postmodern) constructivist accounts do), sexual love is viewed as typically having some phenomenological—subjective, reflexive, first-personal-tendencies or directions. There is, in other words, something first-personal to get right about these things, and getting it right can neither be reduced to an empirical (third personal) question, a (purely self-reflectively available) rational idea of soul-types, or the fact that our rational reflective capacities enable us to choose (with more or less resistance) in response to our desires. 
Moreover, a general suggestion here is that in order to capture sexually loving desire's typical motivational strength, as well as its somewhat unruly nature, categories like Kant's "natural vital force" and "animality" must do important philosophical work. These ideas enable us to capture ways in which there are reflexively (and not reflectively) self-conscious aspects to these parts of us. There are conscious, animalistic strivings of a self centrally involved in sexual love, but this doesn't mean that this striving is inherently reflective all the way down, although it is accompanied by reflective powers from the start. Rather, on this approach, realizing one's sexually loving capacity well involves learning to attend to høw one feels a complexity of concerns with regard to one's own and other's sexual loving ways and how to develop, transform, and integrate these areas of ourselves into stable wholes that are consistent with treating oneself and others as having dignity. Hence, viewing our sexually loving ways as having certain, basic phenomenological tendencies is compatible with how mature and flourishing sexualities typically are characterized by a genuine openness to fluid experiences, new developments, and transformations. For example, it is not uncommon that people who both genuinely like sexual love and like living together in couples also enjoy occasional sexual experiences involving more people, such as those available in sex clubs.

On the Kantian account advanced here, the general story of our sexually loving selves goes something like this: we all have an embodied forcefulness (a natural vital force) that has three animalistic prongs to it, as they are enabled by the three relational categories of the understanding: self-preservation (substance), sex drive (causality), and affectionate community (community). These are conscious strivings of a self, and when things go well and these strivings are satisfied in good ways, we feel strong and harmonious. 
To bring out the structure of this Kantian account, sketching an ideal of what good child development looks like, as well as some common challenges internal to this development, is useful. To start, on this account, a human baby drinks milk as long as the baby is hungry (as long as drinking is pleasant and the pain of hunger is going away) and as it is doing this, it feels strong and increasingly content until there is no more pleasure from the activity (and discomforts make an entrance). In Kantianese, this baby is striving to preserve its animality, and in so doing it feels its natural vital force as strength and this guides the activity (through pleasure and pain). This striving is, then, the baby's nascent ability to sustain itself - self-preservation - as a biological being. Similarly, a human baby is calmed and feels pleasure at being held close and being attended to affectionately; basic community (or sociality in this sense) is also a natural striving for us. Finally, a human baby is incredibly receptive to human touch, which is not only a way in which we seek basic community, but also reveals our innocent, nascent sex drive; a baby experiences it as pleasant to touch others and feels pleasure in light physical, playful touch. As with eating and affection, however, this is a nascent ability, the development of which is constitutive of growing and maturing. For example, as babies, after we have eaten ourselves full, been attended to in gently, sometimes playful ways, and then held in affectionate ways, we feel content, safe, and peaceful - and as this happens, we become ready to rest and often fall asleep. To express this point in Kantianese, we can say that in this case, our natural vital force is successfully attended to, engaged, and developed by our conscious strivings for selfpreservation, sexuality (touch), and basic community. In addition to these natural, animalistic drives, Kant proposes that, from the start, we can see nascent human freedom present in the fact that only human babies scream: the scream is only possible to explain philosophically if we attribute to the baby the capacity to represent its inability to act as a frustration. A baby cannot 
do anything yet, which is experienced as extremely frustrating — and so we scream when we are born $\left(\mathrm{A}^{\mathrm{x}} 7: 268\right) .{ }^{\mathrm{xi}}$ Also, notice that if all of these three animalistic drives are realized well together as a whole and the frustration regarding freedom is handled well by the caregivers, a baby is harmonious and strong; in Kantianese, its natural vital force is experienced as strong and calm. Correspondingly, caregivers' early aims centrally involve facilitating an environment in which a baby can strive in such unified, good ways.

The story about good human sexual love, in turn, becomes a story where one develops this starting point with the rest of Kant's account of human nature (humanity and personality, in addition to animality) as well as with other ideas from his aesthetic-teleological thought and practical philosophy. ${ }^{\text {xii }}$ For example, as a baby develops a social sense of self (as revealed in smiling at and with others and also starting to have emotions revealing a longing for attention, including as revealed in jealousy) and the ability to act (as evidenced in activities like reaching for objects, rolling around, crawling, walking, etc.), the baby is simultaneously developing several cognitive abilities. As we learn to navigate the world, we learn to associate objects with pleasures and pains, to master abstract concepts, to manage the power of choice (at first evidenced in the period of learning the power to say "no" when asked by caregivers if one wants various things), to experience aesthetic pleasures of the agreeable (what one likes) and of the beautiful and the sublime (to be aesthetically deeply pleased or struck), and to hold things together in teleological wholes (including as stimulated by various children's games involving combining). Moreover, as our baby selves are learning all of this, at some point, we are also able to relate to what we are doing not only through abstract concepts ("mummy," "milk," "play"), but also as an "I" (we switch from describing ourselves in the third person singular ("Hannah") to the first person singular) and we start to display and develop temperamental qualities. Some of 
us, for example, reveal ourselves as having more introverted or more extroverted emotional patterns, or, if we use Kant's categories, we reveal ourselves as having "sanguine" (joyous and spontaneous), choleric (dramatic and in need of much attention), melancholic (forcefully serious, thoughtful, and careful), or phlegmatic (calm and somewhat inactive or deeply reflective) patterns. In themselves, these temperamental patterns are neither good nor bad, but rather involve specific kinds of emotional dis-/advantages with regard to mastering feeling or activity.

As we are learning how to do all of this—and we'll get back to spelling this out regarding sexual love in a moment-we also experience the propensity to do bad things. On Kant's account, this characteristically involves three kinds of experiences: we have experiences where we know we shouldn't do something, but then we do it anyway ("frailty"); we realize that sometimes we do what is right, but that the reason why we do it is not praiseworthy or stable ("impurity"); and finally, we experience doing bad things in the name of doing good things (“depravity"). Also, throughout all of this learning, transforming, and integration, we become increasingly able to act on practical reasons, meaning that we become increasingly able to use abstract concepts to set ends we want to pursue (act on "maxims") as well as to do or not do something just because it right or wrong to do (act on a moral motivation or out of "duty"). The human being, in other Kantian words, becomes susceptible to "moral feeling" (the moral "ought") or develops a "personality" and a "conscience"; we become capable of moral responsibility. Living life as a growing and maturing little human being—or its caregivers—is, in other words, not easy, and complications are added by the fact that we live our first many years (before we are capable of even minimal moral responsibility) within the bubble of our given families with all their (often rationalized) immaturities and dysfunctions. 
On this approach, it is therefore important to realize that we start this project in nascent ways much before we are capable of morality and we are extremely dependent on having caregivers around who provide us with an environment in which we can safely make this our own project—one that hence starts from a place of sexual innocence. In part, providing such an environment involves setting clear boundaries around each child in the home, boundaries that no one is permitted to intrude upon. The bare minimum in this regard is obyiously for the caregivers not to cross these boundaries themselves by engaging their children in sexual activities or by permitting anyone else (adult or otherwise) to do so. ${ }^{\text {xiij }}$ However, generally, a good home also involves intimate personal space for each where one can safely be with oneself and which everyone else regards as crucially important to stay out of. In addition, the challenge is for caregivers to provide safe support and non-judgmental guidance as their child tries to figure out how to love sexually in ways that are consistent with their self- and other-regarding sexual desires, their need to learn to preserve themself (to love sexually safely), and their need for affectionate love and care from others. Central here is therefore not only to learn how to feel sexual pleasure strongly, including how our own bodies work in these regards, as well as to learn to try and fail and try again, but also to manage not simply always to act on sexual desire or not to act in self- or other destructive ways. In addition, we have to learn how to develop, integrate, and transform our sexuality with our appreciation of aesthetic pleasure- feeling oneself and others as lovable and even beautiful and/or sublime — by developing attention to the ways in which others can both complement us in wholes of various aesthetic kinds and strike us as pleasing, wonderful, and/or sexually exciting to be around. And, as mentioned above, we have to learn to do this as the kind of persons we are. If we typically feel strongly and deeply over time (melancholic), for example, or instead tend to feel strongly and playfully in the moment 
(sanguine), then it's important to take this into account as we pursue sexual love. We have to figure out what we can handle emotionally and what is best for ourselves. For example, is it best for us to sexually love someone who is a little similar to or who is a little different from us in these regards, or does this difference not really matter? We have to learn to manage emotions of comparison, such as envy and jealousy, and we must learn how to reject or be rejected by others. What is ours to have is both something we want and the other wants us to have.

To illustrate this point with Kant's accounts of affect and passion, ${ }^{\text {xiv }}$ Kant suggests that affect is prior to reason or involves barring or numbing reason, while passion involves deeply wanting something I cannot have - something that isn't mine to have - and not being able to treat it as such by obsessing about having it. So, if I find someone very sexually attractive, this can involve affect: I can find myself having a feeling that I don't want to explore conceptually (think about) but just go with it and see where it takes me. If the other person also wants this, then there is mutual affective attraction. This basic attraction is something the attracted parties can —individually and together - develop further by learning to understand the nature of the attraction, such as how to stimulate it further or turn it into a stabilizing and constructive force in their lives - by using associative, abstract conceptual, aesthetic-teleological means that are attuned to their temperaments and situations.

If the affect isn't mutual or if it stops being mutual, however, then the danger of passion develops. In fact, Kant argues that sexual love itself can develop into a damaging, obsessive passion is if it is not reciprocated (A 7:266). Moreover, he argues that unrequited love, "[1]ike all passionate longings... gnaw[s] and consume[s] the heart or, so to speak, bind[s] the vital force with shackles" (PMF ${ }^{\mathrm{xv}}$ 15: 940) and "the capacity of the understanding is of little help against it; for the end of enchanted human being sees very well indeed the reasons against [their] favorite 
inclination, but... [they feel] powerless to give them active emphasis" $\left(\mathrm{MH}^{\mathrm{xvi}} 2: 261\right){ }^{\mathrm{xvii}}$ For example, after a breakup, the danger is that not only affect—say, anger, disappointment, or sadness - but also that passion will develop because one is or both are unable to move on, and instead they obsess about what history has shown doesn't work well, such as by it not being transformable into something stabilizing. Hence passion is revealed in how one keeps prodding at something even when doing so doesn't make rational sense and entails that one gets trapped in the past and obsessed with what clearly cannot be. Importantly, such obsession isn't properly responsive to reasoning in that when one obsesses in these ways, one knows that doing so is bad. The reason why reflective cognitive powers are somewhat powerless with regard to passion is exactly because sexual love is, at its base, animalistic and only reflexively self-conscious. Knowing that there is nothing one can do or that the relationship was destructive in nature is sometimes not enough for us to be able to let go as the feelings involved are strong and somewhat irresponsive to practical reason (moral reflection).

On the flip side, strong sexual love is also unruly because of how it is so very energizing. It can give us subjective experiences of strong natural vitality as well as of being deeply attractive, important, and good. It can empower us, in other words, with aesthetically charged, complex subjective experiences of our animality, humanity, and moral feelings - individually and as a package. Moreover, developing sexual love well-including as it involves giving oneself to others in vulnerable, playful, and rightly trusting ways, and giving them affirmation and intimate attention - makes it easy to associate one's sense of self only with the other's presence, rather than holding onto it as also something one has in oneself. Losing such a relationship — whether through heartbreak or death — is consequently often experienced as ungrounding and/or as giving rise to destructive, passionate desires of obsession. Oftentimes, the 
best we are able to do for a while might just be to avoid doing bad things and to try to keep going on one's own in a different direction, since letting go fully or learning to live with the fact of how life will be from now on is emotional work that is partially unreflective and constitutive of our selves all the way down.

It follows from the above account that developing our raw sexual desires into more mature versions centrally involves three main activities of development, transformation, and integration - namely those involved in realizing it as integral to developing also the other parts of our animality (self-preservation and basic community) as well as our humanity (social sense of self and rational end-setting) and personality (moral responsibility) -and to do all of this in ways attuned to our type of temperament and aesthetic-teleological sentiments. All of these emotional structures are resources if we dare to learn to attend to, become familiar with, and understand them. In addition, developing our sexual desires constructively requires us to learn to manage our unruly temptation to act destructively toward ourselves and toward others (evil) and to support our partners in their efforts to do the same-and to hold ourselves and each other accountable when we fail. Moreover, in all these projects of healing, managing, integration, development, and transformation, we use combinations of associative, abstract conceptual, and aestheticteleological tools. If we do all of this well, our sexually loving way becomes constitutive of what Kant calls "the highest good," namely our individual unions between happiness and morality, where our commitment to morality — to treat others as having dignity—sets the framework within which we pursue happiness in the various situations in which we find ourselves. ${ }^{\text {xvii }}$

Another core Kantian proposal that we consider important is his suggestion that the most important general duty we have is to learn to be truthful. Kant's judgment is that most people never take on this challenge, and those who do typically don't make this commitment until in 
their thirties. Moreover, he suggests, if we look at those who really do try, becoming more reliably successful at truthfulness doesn't tend to occur until in their forties (A 7:294). Why such emphasis on the importance of truthfulness? One reason, in this context, is simply that without truthfulness, it isn't possible to develop, transform, and integrate one's sexual loving aspects in associative, abstract conceptual, and aesthetic-teleological ways that are harmonious with one's natural forcefulness and temperament. After all, if one is not truthful, one will not learn to feel one's natural vital force strongly, nor how various kinds of engagements with oneself and others are consistent or inconsistent with harmony and stability in oneself, nor how to describe one's feelings accurately, nor to learn not to act just because the feelings are intense or fiery or deep, nor to be stably around and feel strong feelings without fear. Moreover, without truthfulness, one is much more likely to feel a lot of internal conflict-feelings going strongly in many conflicting directions - exactly because one is not able to ensure that what one is doing is deeply consistent with one's natural vital force, one's temperament, and one's aesthetic-teleological sensibilities. This, in turn, gives rise to the temptation to numb or suppress one's feelings or let them have fiery outlets of anger or sadness, which only can give rise to more dysfunction and destructive pathologies. Another core reason why truthfulness is so important on this approach is that it is constitutive of learning how to develop, transform, and integrate all these emotional aspects of oneself in ways that are respectful of oneself and others as having one's own life to live-a life that we should treat as precious or as having dignity. More specifically, truthfulness is necessary to enable one's conscience to function properly: to hear the call of never treating oneself or others as mere means (to obey our practical reason's command of "perfect duties," as Kant would say) and to feel the obligation to learn to be kind, non-judgmental, and supportive of 
ourselves and each other in our efforts to feel and live better, more fully on our own and together (to obey our practical reason's command of "imperfect duties," as Kant would say). Living in this way is also only possible if one strives to develop a reliable ability to do what is right because it is right when this is called for (to develop "moral character," as Kant would say). Again, sometimes this only involves learning to let go or not to act even though one feels very aroused or sexually excited (so, not to act on affect); other times it is to learn to move on after somebody whose sexual love has been very important is no longer there, such as when sexually loved ones die or when the sexual love changes direction and attention (so as to not develop passion).

Overall, then, our aim regarding sexual love is to strive for a sustainable union between it (as part of our pursuit of happiness) and morality. Because of the emotional complexity of the project - including the different degrees of reflectivity and motivational strength of the various components and the fact that everybody else too has this complexity-realizing a good sexually loving life requires one to address and deal with much arrested development and dysfunction in oneself and one's sexually loving partners. And because sexual love naturally is also rather fiery $^{\mathrm{xix}}$ and unresponsive to reason, it can be tempting to give up on it and instead settle for trying to focus the energy on making the organic whole of one's animality sustainable through time by striving for predictably comfortable, pleasing sex with one partner and for affectionately loving this partner (and possible children) in self- and other-preserving ways. Saying that sex can also be more than this is not to say that there's anything wrong about predictably comfortable sex as such, nor to deny that these kinds of sex have a good and stabilizing role for many or in many circumstances. Rather, the point is simply that for many people sex can be more-including less predictable, more challenging, and more uncomfortable without thereby being bad - and that 
allowing and pursuing more when life allows can be a wonderful part of life. ${ }^{\mathrm{xx}}$ It is typically not easy, though, given the societies we inherit with their histories of oppression and the related dehumanizing violences we can become subjected to.

\section{Patterns of Dehumanization and the Possibility of Sexually Loving Lives}

While our sexuality has a certain basic phenomenological direction to it, because our feelings are susceptible to associative thought, and because much oppression is expressed in rationalized ways, it is also the case that various social norms and institutions shape our sexualities in ways we are unaware of. The social world in which we live shapes our sense of which forms of sexual love are possible and which are deemed valuable and desirable for people like us. It informs which sexual experiences are open to us, which are encouraged or incentivized, which are forbidden (though possibly still desired), which feel frightening or unimaginable. Through an interrelated set of social rewards_-ranging from realizing the possibility of being intelligible to oneself and one's community, to peer acceptance and support, to elevated social status, to being considered worthy of finding sexual connection or love - and social punishments - including harassment and assault, social ostracism, and outright group expulsion (or even just the mere threat of these things) — our sexualities are profoundly influenced by the families and communities in which we find ourselves. Many find themselves torn between the draw of having sex that strengthens their natural vital force and asserts and realizes who they actually are, on the one hand, and the limiting forces of social acceptance or intelligibility, on the other. But the human imagination is powerful, and our sexual desires tend to be unruly, and can refuse to bow to the powerful constraining forces of convention. 
Arendt's account of how both philosophy and modern life undervalue our animality can make sense of some of the ways that oppressive forces cause distinctively sexual harms or injustices. For one, members of oppressed groups tend to be associated with their animality in ways that others are not. Simone de Beauvoir relatedly called out this tendency to depict women as "think[ing] with [their] glands," pointing out that "Man superbly ignores the fact that his anatomy also includes glands, such as the testicles, and that they secrete hormones. He thinks of his body as a direct and normal connection with the world, which he believes he apprehends objectively, whereas he regards the body of woman as a hindrance, a prison, weighed down by everything particular to it." ${ }^{\text {xxi }}$ Women are still too often portrayed as beholden to their animality in ways men are not, held hostage by their irrational hormones, tied down to the animal functions of bearing and suckling children, incapable of transcending the immanence of mundane domestic realities the way men are. Women's unbridled animality is also portrayed as precariously out of control, as ironically both dangerously tempting to men and in need of male control, resulting in a variety of social and religious practices that valorize feminine modesty and make women responsible for men's lust. Similarly, Black people have been characterized as animalistic, both brutish and hypersexual, resulting in depictions of Black men as dangerous predators and Black women as "unrapeable" Jezebels. By associating these groups of people with what are ostensibly the least valuable aspects of human nature, these people are marked variously as not worthy of respect, as deserving harmful treatment, and as needing to be controlled both for their own good and the good of society.

The above Kantian account of human nature, in conjunction with the Arendtian account of the distinctive pitfalls of our overblown modern social selves, can shed further light here, bringing into focus problems with the kinds of sex you might think we should be having but are 
not, and with the kinds of sex we are having instead. One way these social considerations can get in the way of the sex we should be having has to do with how the new identity categories that arose in modernity encourage in-group/out-group identifications that lead to division and conflict. These identifications result in patterned forms of social exclusion that have and will continue to prevent certain loving sexual relationships from even having the chance to begin. Racial and ethnic categories, for example, have been reified and interracial or inter-ethnic sexual relationships historically discouraged or outright forbidden. Anti-miseegenation laws that criminalized interracial marriage (and sometimes also sex between members of different racialized groups) originated in the late seventeenth century in North America and remained on the books well into the twentieth century. Nazi anti-miscegenation statues discriminated against Jewish, Roma, LGBT+, and Black people in Germany; laws in fascist Italy forbade marriages between Italians and Jews or Africans; even today, in some countries, marriages between, for example, Jewish, Christian, and Muslim people are culturally or even legally forbidden, restricted, or discouraged. Of course, sexually loving relationships can and do manage to exist across these arbitrary social lines, and the prospect of breaking a taboo can make boundarycrossing in such contexts sexually exciting. But doing so ethically requires, among other things, vigilant truthfulness and learning to feel and trust what is deeply good for oneself, insofar as such relationships inevitably involve coming up against prejudices held by oneself, one's partner(s), and society at large.

Another considerable temptation of bad sex arises when we unthinkingly adopt the identity categories foisted upon us by society. The risk of doing so is the risk of living a life of sexual bad faith, one that fails to stay true to ourselves. The existential importance of being able to live out one's sexuality in good ways is evident, at the extreme, in the higher suicide rates for 
those who are denied the possibility of doing so. ${ }^{\text {xii }}$ But for too many, a life of sexual bad faith will have us seek out actions or interactions we don't actually find sexually satisfying or fulfilling, but fall in line with what society says that "people like us" are supposed to want. Deeply entrenched heteronormative biases will thus discourage people from exploring queer desires, for example. Classist and racist biases will discourage people from exploring sexual relationships with people from different socio-economic and racialized backgrounds. Ableist biases discourage able-bodied people from exploring sexual relationships with people with disabilities and vice versa, and they discourage people with disabilities from pursuing any sexual interactions whatsoever. Transphobic biases discourage people from expressing their true gender identities, and they discourage cis people from pursuing sexual relationships with trans people.

What's worse, we impose these identity categories onto our children, denying them the opportunity to discover and explore their true sexual or gender identities. Compulsory heteronormativity, and its attendant homophobia and transphobia, denies many the opportunity to live authentic LGBTQIA+ lives. Racism and classism prevent them from forming sexual connections with others across racial, ethnic, or class lines. Regressive prudishness and loathing of animality (often religiously rationalized) gives rise to repression and shame instead of acceptance and encouragement. Socio-economic class inequalities force many parents into lowpaying jobs that leave them with little time or resources to direct toward protecting their children, much less promoting their sexual flourishing. Because racism is positively correlated with both socio-economic oppression and a higher danger of being sexually assaulted, this often puts POC families in a radically difficult situation in these regards.

Just as troubling as the sexual experiences and relationships we are discouraged or forbidden from pursuing are some of those we are encouraged to pursue in their stead, some of 
which are internally connected with dehumanizing violence and oppression. Stereotypes are often instrumental in this process, providing people with limiting social scripts that funnel them into personalities and behaviors that numb their natural vital force, and lead them to desire and pursue sexual interactions that are not merely unfulfilling but are immoral and hence numb their moral vital force. Gendered sexual stereotypes that characterize men as naturally driven by lust and women as naturally chaste, for example, lead to eroticized relationships of gendered dominance and submission that many feminists argue are directly responsible for the disproportionate rates of sexualized violence against women. Racialized sexual stereotypes such as that of the Latina spitfire and Latino machismo, or, again, of Black men as lustful brutes and Black women as unrapeable Jezebels, are internally connected with more sexual violence against women of color and unfair and ungrounded accusations of sexual violence imposed on men of color.

Another way that stereotypes influence the content of people's sexual desire and are internally connected with much dehumanizing violence and oppression occurs through the mechanism of mainstream pornography. Too many pornographic scripts fetishize the objectification, degradation, and humiliation of women at the hands of men. According to Catharine MacKinnon,

Pornography sexualizes rape, batter[y], sexual harassment, prostitution, and child sexual abuse; it thereby celebrates, promotes, authorizes, and legitimizes them. More generally, it eroticizes the dominance and submission that is the [common] dynamic. It makes hierarchy sexy and calls that "the truth about sex" or just a mirror of reality.... What pornography does goes beyond its content: it eroticizes hierarchy, it sexualizes inequality. ${ }^{x x i i i}$ 
Mainstream pornography entrenches sexist stereotypes about what men's and women's sexual natures are supposed to be like: men are portrayed as sexually active, aggressive, and dominant, while women are sexually passive and submissive. Adherence to these narrow sexual stereotypes can encourage people to seek out sexual interactions that are unsatisfying at best, and demeaning or degrading at worst. When such pornography takes the place of a better informed, comprehensive sex education, it stunts people's sexual imaginations and can make them feel compelled to perform certain sexual roles not because doing so actually expresses their true sexual desires, but because they don't have a robust sense of what more authentic alternatives might be.

The concern here is not merely that such stereotypes deny people the space to explore their sexualities in authentic ways, however. The deeper concern has to do with how social and historic forces construct stereotypes that make it difficult or impossible to have morally permissible and emotionally healthy sex - sex that properly treats ourselves and others with respect and that for many can be an important component of a flourishing life.

Kant's thoughts on objectification can fruitfully illuminate failures of respect that arise when people are used as mere means in a sexual context — either when their sexual wishes or desires are ignored, or when they are treated as if what they experience in a sexual encounter does not matter. As explained above, because sexual desire is importantly only reflexive, not reflective, and because of the danger of affects and passion, there is a danger, according to Kant, that sexual desire results in such objectification. Because sexual desire and pleasure can bring us to subjective experiences of urge in such acute and powerful ways, they can drive out all reflection (other thoughts), including thoughts of the moral respect we're required to have for others. We can bring ourselves into a condition of being turned on that feels like our brains fritz 
in such a way that we can block our conscience's demand for us to respect someone and make sure that what we want is also what they want. "In that condition of mind," characterizes Martha Nussbaum, “one cannot manage to see the other person as anything but a tool of one's own interests, a set of bodily parts that are useful tools for one's pleasure, and the powerful urge to secure one's own sexual satisfaction will ensure that instrumentalization (and therefore denial of autonomy and of subjectivity) continue until the sexual act has reached its conclusion. At the same time, the keen interest both parties have in sexual satisfaction will lead them to permit themselves to be treated in this thinglike way by one another."xxiv Kant thought this is a two-way street, that men and women do this symmetrically to each other. To desire someone sexually, then, can involve wanting to objectify them and wanting to let them objectify you. This is morally dangerous or problematic (depending on the interpretations), Kant thought, because it can lead us to both fail to respect other people and to fail to respect ourselves — and, so, can be damaging to all parties involved. ${ }^{x x v}$

Kant himself didn't realize this, but many such failures of respect are patterned in gendered ways. Contemporary feminists such as MacKinnon and Andrea Dworkin have taken up this Kantian account of what is wrong with sexual objectification, but unlike Kant do not believe that these dangers or problems are inherent to sexual desire itself. Instead, they lay the blame at the feet of how we are socialized erotically, into a paradigm shot through with gendered hierarchy and domination. The failures of respect resulting from sexual objectification are not symmetrical, according to these feminists. Rather, in ways reminiscent of Beauvoir, these thinkers argue that men are taught to experience sexual desire by dominating and using women, and women are taught to experience sexual desire by being dominated and turned into sex objects. Moreover, these gendered asymmetries in our erotic imaginations have real-world 
consequences. MacKinnon and Dworkin argue (somewhat controversially) that the eroticization of these gendered relationships of dominance and submission is directly causally responsible for women's disproportionate risk of sexualized violence at the hands of men. Rae Langton argues that these pornographic scripts create a social world in which women are objectified, depicted as existing "for sex," and where their attempts to refuse sex are portrayed as integral components of erotic scenes. ${ }^{\text {xxvi }}$ Even if a direct causal connection between these pornographic tropes and sexualized violence against women cannot be established, the morally problematic patterns are clear enough. Ours is a social world in which people are encouraged to internalize gendered identities and erotic scripts that make deep, flourishing sexual love impossible to experience for many and that make morally respectful interactions very difficult.

\section{Concluding Remarks}

In the societies in which we currently live, realizing sexual love well in less traditional waysqueer sex, for example, or kinky sex, or BDSM sex, or sex therapy, or sexual experiences enabled by sex experts - typically requires wisdom with regard to how to protect and realize one's sexuality in flourishing ways, as well as safe spaces in which desires can be explored. Such spaces can offer a respite from the oppressive forces of social convention precisely because these communities have had to struggle at the margins for social recognition and acceptance, and even the right to exist at all. Members of these communities are more likely to have done the work of reflecting deeply on their own desires, and are thus less likely to be susceptible to bad faith in important regards, because these communities are born of the need to learn to know one's authentic desires when acting on prominent social conceptions is impossible without being selfdestructive. Such communities also tend to be profoundly incentivized to ensure that their 
members' desires are pursued in morally permissible ways, and thus tend to have highly evolved norms of sexual communication and consent - including, for example, practices such as safe words. ${ }^{\text {xxvii }}$ These spaces are also ones in which serious violence can occur, however, including by being tempting to people who have serious inabilities to own who they are and are thus inclined to engage in behavior that is destructive of both themself and others. Still, communities such as these, which typically exist at the margins of society, often have insights that would be helpful also if they were taken up by the mainstream.

* Thanks to Lucy Allais, David Boonin, and Shelley Weinberg for their generous help along the way of writing this paper.

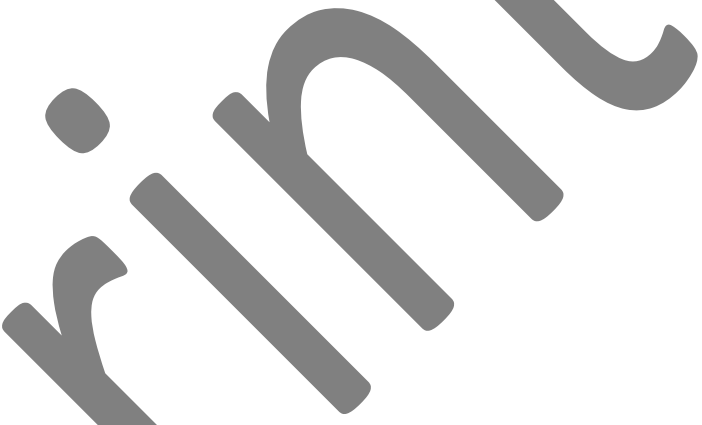

i For more on Kant's philosophical mistakes and deep, personal discomfort around these issues as well as references to much of the related literature, see Helga Varden (2020). Sex, Love, and Gender: A Kantian Theory. Oxford: Oxford University Press.

ii By this, we simply mean that way in which we engage the world in part by viewing some things as constitutive of wholes For example, the doors, stairways, windows, walls, etc. are parts of - in the sense of constitutive of $-\mathrm{a}$ house.

iii Given our aims in this paper, engaging in all the related interpretive debates in the Kant community would take us in the wrong directions. For more on some of these debates, see (Varden 2020) and for Kant's account of the predisposition to good and the propensity to evil in human nature, see his (1793/1999) Religion with Boundaries of mere Reason: and Other Writings, eds. A. Wood and R. di Giovanni (Cambridge University Press), starting with the sections "Concerning the Predisposition to Good in Human Nature" and "Concerning the Propensity to Evil in Human Nature," (6: 26-33).

iv See Arendt's (1958/2018) The Human Condition. Chicago: University of Chicago Press. 
v See Arendt’s (1951/1973) The Origins of Totalitarianism. Harcourt, Brace, Jovanovich.

${ }^{v i}$ See Arendt's (1963/2006) Eichmann in Jerusalem: A Report on the Banality of Evil. Penguin Classics.

${ }^{v i i}$ See Arendt's (2018) Thinking without a Bannister: Essays in Understanding (1953-1975). Schocken Books.

viii "Self-reflexive" consciousness means an awareness internal to any thought or action, whereas "self-reflective" consciousness means a first-personal thinking about what one is thinking or doing and that one is the one doing it. Self-reflective consciousness is a second-order awareness of what I am already self-reflexively conscious of.

ix Exploring some of the choice vs. essence themes is a central topic in (Varden 2020).

x Immanuel Kant (2007). Anthropology from a Pragmatic Point of View in Anthropology, History, and Education, ed. by Robert B. Louden and Günter Zöller, transl. by Mary Gregor, Paul Guyer, Robert B. Louden, Holly Wilson, Allen W. Wood, Günter Zöller, and Arnulf Zweig. New York: Cambridge University Press.

xi We also cry, and we cry because we've been separated from the being we've been inside of, and so we long for unity again — something that is satisfied by being put on our caregivers' bodies and being swaddled. This, however, is consistent with the scream, and it is consistent with many other newborn animals being put together with others or being held close by their parents. The other animals don't scream when born, however, and that's what Kant wants us to be able to explain.

xii For more on all of these points and the other ones covered below, see (Varden 2020). For many other Kantian ideas of emotionally healthy, morally responsible self-realization, see also Carol Hay (2013). Kantianism, Liberalism, and Feminism: Resisting Oppression. Palgrave Macmillan.

xiii On this account, feeling such desires reveals that one has some rather deep, repressed sexual immaturities that one needs to take seriously and shed light on so that they can be matured in responsible ways - and because they will involve reflexive desires, the best way to do this is with the help of excellent therapists. For example, psychoanalysts are exactly trained in engaging our so-called "sub-conscious" desires.

${ }^{\text {xiv }}$ Kant's discussions of affects and passions are spread throughout his works. A good place to start is his discussion in Anthropology from a Pragmatic Point of View in Anthropology, History, and Education.

xv Immanuel Kant (2007). “On the philosophers' medicine of the body” (PMB), in Anthropology, History, and

\section{Education.}

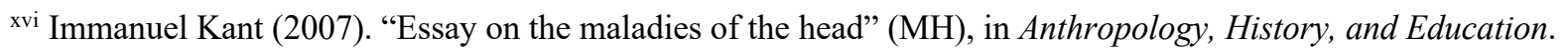


${ }^{x v i i}$ Note that we have changed the translation into the gender-neutral noun (they) here to make it more true to the original German.

xviii Kant's idea of the highest good is found many places in his practical works. For example, see "On the common saying: That may be correct in theory, but it is of no use in practice" (8: 279) and Critique of Practical Reason (5: 110-115). Both texts are printed in Kant, Immanuel (1996). Practical Philosophy, transl. and ed. by Mary J. Gregor. New York: Cambridge University Press.

${ }^{\text {xix }}$ For two classic, Kantian interpretations of sexual love's fiery nature, see Christine Korsgaard's proposal that it is inherently "possessive” (in her 1992 article 'Creating the Kingdom of Ends: Reciprocity and Responsibility in Personal Relations', in ed. J. Tomberlin Philosophical Perspectives, 6, Ethics, pp. 305-332, Atascadero, CA: Ridgeview Publishing Company) and Barbara Herman's proposal that it is inherently “objectifying” (in her 1993 article “Could It Be Worth Thinking about Kant on Marriage?", in eds. Louise M. Antony and Charlotte E. Witt $A$ Mind of One's Own: Feminist Essays on Reason and Objectivity, pp. 53-72, Cambridge: Westview Press)).

${ }^{x x}$ For a wonderful Kantian interpretation of many of the functions and types of sex, see Jordan Pascoe (2012). 'Hunger for you: Kant and Kinky Sex', in S. M. Kaye (ed.) What Philosophy Can Tell You About Your Lover, pp. 25-36. Open Court Press.

xxi Simone de Beauvoir, The Second Sex, ed. and trans. H.M. Parshley (New York: Vintage, 1989 [1949]), xxi. xxii Ann P. Haas, Philip L. Rogers, and Jody L. Herman (2014). Suicide Attempts among Transgender and Gender Non-Conforming Adults: Findings of the National Transgender Discrimination Survey. New York and Los Angeles: American Foundation for Suicide Prevention and the Williams Institute (williamsinstitute.law.ucla.edu/wpcontent/uploads/AFSP-Williams-Suicide-Report-Final.pdf).

xxiii Catharine MacKinnon, "Pornography, Civil Rights, and Speech," Harvard Civil Rights-Civil Liberties Law Review 20, no. 1 (1985): 462.

xxiv Nussbaum 266-267.

${ }^{\mathrm{xxv}}$ For more on some of these discussions, see (Hay 2013) and (Varden 2020).

xxvi Rae Langton, “Speech Acts and Unspeakable Acts," Philosophy \& Public Affairs 22, no. 4 (1993): 293-330.

xxvii Quill Kukla, writing as Rebecca Kukla, “That's What She Said: The Language of Sexual Negotiation,” Ethics 129, no. 1 (2018): 70-97. 